\title{
A CABAÇA-ÚTERO DE ÒSUN:UM OLHAR PARA O CORPO MATERNO NA LITERATURA BENINENSE
}

\author{
ÒSUN'S CABAÇA-ÚTERO: A LOOK AT THE MATERNAL BODY IN LITERATURE FROM BENIN
}

\section{RESUMO}

O presente artigo realiza um estudo sobre as personagens femininas em Presqu'une vie e Pour une poignée de gombos, das escritoras Carmen Toudonou e Sophie Adonon, respectivamente. As narradoras que tecem as histórias retratam aspectos que envolvem o universo feminino, desde seus papéis sociais no Benim enquanto mulher e esposa, como também as suas ligações com o sagrado e a ancestralidade, vivências que as conduzem para superação das opressões que as cercam. Nossas análises serão voltadas para as experiências destas personagens femininas com a maternidade, observando os lugares nos quais elas estão inseridas e compreendendo as diferentes relações que elas estabelecem com o seu corpo materno e com o ato da maternagem. Como aportes teóricos, nossas análises seguirão à luz das contribuições teóricas de bell hooks, Sylvia Tamale, Nkiru Nzegwu, Oyèrónke Oyewùmi e Carla Akotirene. Com relação aos conceitos sobre maternidade, nos apoiaremos na ideia de Feminismo Matricêntrico, de Andrea O'Reilly; Other-mothering e Mothering of the mind, de Patrícia Hill-Collins e Motherism, de Catherine Acholonu.

Palavras-chave: Maternidade. Literatura Beninense. Autoria Feminina. Carmen Toudonou. Sophie Adonon.

\begin{abstract}
The following article analyzes the female characters in Presqu'une vie and Pour une poignée de gombos, written by Carmen Toudonou and Sophie Adonon, respectively. The storytelling narrators portray aspects which involve the female universe; from their social roles in Benin as woman and wife, as well as their links with the sacred and ancestry, experiences that lead them to overcome the oppressions surrounding them. Moreover, our perspective will be focused on the experiences of these female characters regarding motherhood, observing the places they are inserted, and understanding the different relations established with their maternal body and the act of mothering. As a theoretical framework, our analysis will consider the contributions of bell hooks, Sylvia Tamale, Nkiru Nzegwu, Oyèrónke Oyewùmi and

Maysa Morais da Silva Vieira

Doutoranda em Estudos Culturais e de Gênero, no Programa de Pós-Graduação em Letras (UFPB). Mestra em Estudos Culturais e de Gênero (PPGL/UFPB). Graduada em Letras - Língua Portuguesa (UFPB). E-mail: maysa.morais@yahoo.com.br.

Luciana Eleonora Calado de Freitas Deplagne

Doutora em Letras pela Universidade Federal de Pernambuco (2006), com estágio doutoral (com Bolsa da CAPES) na Université Blaise-Pascal, em Clermont-Ferrand, na França (2003-2004), e pós-doutorado pela Universidade Nova de Lisboa (2015-2016). Professora Associada I do Departamento de Letras Clássicas e Vernáculas da UFPB. E-mail: lucianaeleonora@yahoo.com.br.
\end{abstract}


Carla Akotirene. As for the concepts of motherhood, we will be using the idea of Matricentric Feminism, coined by Andrea O'Reilly; Other-mothering and Mothering of the mind, by Patrícia Hill-Collins; and Motherism, by Catherine Acholonu.

Key words: Motherhood. Beninese Literature. Female Authorship. Carmen Toudonou. Sophie Adonon.

\title{
Considerações Iniciais
}

\author{
“[...] Nas águas de Oxum \\ sou peixe de barriga cheia \\ atingida pela flecha certeira. \\ Trago no ventre o poder de gerar, \\ explodirei água \\ explodirei sorte \\ Ominirê" \\ (Mel Adún)
}

Nos últimos anos, a literatura beninense tem ganhado importantes nomes femininos, dentre eles as autoras cujas obras são objetos de estudos neste artigo. A escritora Sophie Adonon, que nasceu em Abomey em 1964. No ano de 1983, mudouse para França onde estudou direito e concluiu o mestrado em Direito Privado em 1990. A romancista foi a primeira beninense a criar uma série policial e a primeira cujo livro foi colocado no programa didático das escolas do ensino fundamental e médio do Benim. Dentre os livros publicados pela autora, podemos citar: Le sourire macabre (2011); Le plat qui se mange froid (2011); Coeur insomniaque (2012); Paroles d'immondices (2013); Pour une poignée de gombos (2013); Les hiatus (2014); Un trop lourd tribut (2015); Bitume fertile (2015); Monarque Hangbé: panégyrique d'une Reine bifée (2016); Assouka (2016); Adjoua et ses échelles (2017); Échos de femmes (2018); Mourir ou mourir (2018); Parole citée (2019).

Por sua vez, Carmen Toudonon é poetisa, romancista e repórter-apresentadora do Escritório de Rádio e Televisão de Benin (Ortb). Possui poemas publicados no livro Anxiolytique, uma antologia de poemas de autoria feminina, organizada pelo escritor Daté Atavito Barnabé-Akayi e publicada em 2013. E além do romance Presqu'une vie (2014), publicou a coletânea poética Noire Venus (2015) ; Le vert, le rouge et le noir Sémiologie des grades et appellations dans l'armée de terre béninoise (2017); Carmen Fifonsi Aboki (CFA) (2018); Le lionceau et le papillon (2018) e, recentemente, lançou o romance Tant de gens espèrent être aimés et beaucoup ne sont que mariés (2020).

As escritoras beninenses têm conquistado espaços importantes no quadro literário do Benim e dos países africanos de língua francesa, apesar de uma imensa desigualdade que perdurou durante anos, desde o surgimento dos primeiros textos literários no país. Em suas obras, há uma preocupação em retratar as vivências das mulheres, seus escritos carregam as heranças das guerreiras reais do Daomé, as 
Ahosi, e nos mostram como a luta para desvencilhar-se das diferentes condições que as oprimem sempre fez parte dos sujeitos femininos beninenses.

Para este artigo, nos interessa observar as relações com a maternidade vivenciadas pelas personagens femininas Julienne, Régisette, Bäi, Séréna e Dansi, no romance Pour une poignée de gombos, de Sophie Adonon que teve sua segunda edição publicada em 2016, pela Éditons GG, em Cotonou. Como também a personagem Abluimadji em Presqu'une vie, romance de Carmen Toudonou publicado em 2014, pela editora beninense Plumes Soleil. São estes eventos referentes aos corpos maternos e à maternagem exercida pelas mulheres das narrativas, que norteiam nossas análises, cabendo ainda destacarmos a importância dos cultos religiosos tradicionais do Benim, em especial, o culto aos Vodouns/Orixàs femininos Mamy Water e Òsun, que são responsáveis por guiar as ações das personagens e simbolizam uma cosmovisão sobre corpo, sexualidade e maternagem em diferentes culturas africanas.

Em Pour une poignée de gombos, a narrativa apresenta-se em um ambiente rural e tem uma protagonista feminina, a jovem Julienne, cujo destino é totalmente mudado a partir do momento em que sua mãe Bäi a pede para colher quiabos no campo juntamente com sua irmã mais velha Régisette. É nessa ida ao campo, que Julienne encontra Tony, um jovem que estava de passagem pelo vilarejo. Ambos se apaixonam e se casam logo em seguida, despertando o ciúme de sua irmã Régisette, pois ela era mais velha e o esperado pela sociedade era que ela se casasse primeiro.

Após o casamento, os noivos se mudam do vilarejo para a capital Cotonou. Régisette por ser a irmã mais velha muda-se com o casal para auxiliar a irmã mais nova nos cuidados da casa e do marido. No entanto, a convivência com o cunhado desperta uma paixão, e Régisette e Tony vivem um breve relacionamento amoroso, o que resulta na gravidez de Régisette. Com medo da rejeição, Régisette foge da casa da irmã para que nada fosse descoberto.

Algum tempo depois, Régisette dá à luz ao seu filho e o abandona no templo de Dan (Vodoun patrono do Benim, representado pela serpente), por sua vez o bebê é encontrado por Dansi (nome homônimo ao da divindade Dansi, a serpente feminina irmã de Dan). Por ser uma mulher estéril, Dansi já havia feito diversas oferendas aos deuses para engravidar. Acreditando ser uma resposta dos deuses aos seus pedidos, Dansi cria a criança, chamada de Éros, até por volta de seus 20 anos. Já adulto, Éros conhece a jovem Séréna, filha de tia Julienne e o seu pai Tony, que até então não sabiam de sua existência. Régisette retorna para Cotonou e reencontra o filho que julgava não ter sobrevivido na noite do abandono, descobre ainda o relacionamento entre os irmãos e vê-se obrigada a contar a história que escondeu até aquele momento. Prestes a se casarem, Éros e Séréna descobrem que são filhos de Tony e têm suas vidas devastadas pelo segredo que vem à tona.

Em Presqu'une vie, temos a narradora-personagem Abluimadji, a protagonista do romance, que, por meio de um resgate mnemônico, tece sua trajetória de vida. $\mathrm{O}$ velório de seu pai dá início à narrativa, e permite que a personagem volte à sua infância e mostre suas relações com a família. Essa memória é marcada por lembranças da não-aceitação de seu pai quando descobre que a quinta criança a nascer era uma 
menina. Sendo a única filha entre os seus irmãos, Abluimadji sempre se esforçou para se destacar e conquistar espaços. Na escola, por exemplo, ela tinha um ótimo currículo, causando espanto em seu pai e irmãos. Os aspectos do sagrado e culto aos vodouns, divindades espirituais cultuadas no território do Benim, permeiam a narrativa. Abluimadji possui ligações importantes com o sagrado, já que até mesmo a sua vinda ao mundo foi uma imposição dos vodouns à sua mãe. Portanto, ainda criança, a personagem é iniciada ao culto aos vodouns, o que, ao longo de sua vida, configura-se como um processo de autoconhecimento e resistência para superar as dificuldades que apareceriam na sua vida.

Na adolescência, Abluimadji, mesmo sendo uma aluna brilhante na escola, precisa abandonar os estudos. Isso ocorre devido a fatores econômicos da família, pois não podia arcar com a educação de todos os filhos priorizando, assim, a permanência dos meninos na escola. Mas também por uma questão cultural, Abluimadji se prepararia para o cumprimento do destino de todas as outras meninas na sua idade: o casamento. Durante o seu noivado, Abluimadji conhece um outro rapaz e vive com ele um romance às escondidas do qual a personagem engravidará. Para fugir dos julgamentos sociais e, sobretudo, da rejeição da família, a personagem esconde a sua gravidez e decide que dará à luz a criança, mas que logo em seguida a abandonará.

Após anos longe de sua cidade natal, Abluimadji retorna durante as festividades dos vodouns locais e encontra sua filha já crescida. Após ser abandonada pela mãe, a criança foi encontrada e criada pelo líder religioso da comunidade e sua esposa. Eles sempre souberam de quem a criança era filha, pois os vodouns os informaram mediante consultas feitas ao jogo de búzios. O casal também previamente sabia e, portanto, já aguardava por esse reencontro. Em Presqu'une vie, podemos observar que a narradora-personagem Abluimadji, apesar de não sair de sua comunidade local, apresenta e questiona sua situação enquanto mulher que vive diversas situações que a oprime, exprimindo sempre um desejo de não se desvencilhar das suas raízes ancestrais, mas sim de transgredir valores tradicionais que ferem a sua existência.

\section{A potência feminina refletida no abèbè d'Òsun}

O corpo negro e, em particular, o corpo da mulher negra, sofreram e ainda sofrem múltiplas violências resultantes dos processos que estes sofreram ao longo dos séculos até os dias de hoje. Ao chegarem em África, os colonizadores brancos inferiorizaram os povos africanos subjugando seus corpos, suas línguas e suas religiões pelo critério da raça, vista por esses como inferior, e a mulher africana pelo viés do gênero, também sofreu mais essa violência. bell hooks, em sua obra Intelectuais Negras, nos diz que:

O sexismo e o racismo atuando juntos perpetuam uma iconografia de representação da negra que imprime na 
consciência cultural coletiva a ideia de que ela está neste planeta principalmente para servir aos outros. Desde a escravidão até hoje o corpo da negra tem sido visto pelos ocidentais como o símbolo quintessencial de uma presença feminina natural orgânica mais próxima da natureza animalística e primitiva. (HOOKS, 1995, p. 468)

A partir dos processos de colonização e escravização dos povos africanos, esses sujeitos viram, tanto no território africano quanto na diáspora, perpetuar diversos estereótipos racistas e sexistas que colocam o seu corpo e sua sexualidade em um lugar não-humano, de objetificação e meramente destinado a uma função hiperssexual. Frantz Fanon, em Pele Negra, Máscaras Brancas, é enfático ao afirmar que:

Para a maioria dos brancos, o negro representa o instituto sexual (não educado). O preto encarna a potência genital acima da moral e das interdições. As brancas, por uma verdadeira indução, sempre percebem o preto na porta impalpável do reino dos sabás, das bacanais, das sensações sexuais alucinantes... Mostramos que a realidade desmente todas essas crenças. Mas tudo isso se acha no plano do imaginário, ou, na pior das hipóteses, no do paralogismo (FANON, 2008, p. 152).

As práticas e costumes culturais e o modo como os africanos se relacionam sexualmente e afetivamente, sobretudo no que se refere ao comportamento social das mulheres africanas que divergiam bastante das mulheres europeias, causavam impactos aos colonizadores. O protagonismo das mulheres na sociedade seja como chefes de família ou lideranças de grupos de guerreiras era visto como não-femininos e, portanto, responsáveis por uma visão masculinizada destas mulheres, além disso os relacionamentos poligâmicos/poliândricos, comuns em muitas sociedades africanas, eram igualmente motivo de espanto para os padrões judaico-cristãos europeus. A ugandense Sylvia Tamale descreve que:

As sexualidades das mulheres africanas, no entanto, foram caracterizadas como a antítese dos costumes europeus de sexo e beleza e foram rotuladas de primitivas. As memórias de viagem da década de 1860 do explorador inglês Sir Richard Burton, por exemplo, descreveram as mulheres que ele encontrou no reino de Daomé (atual Benim) como "horríveis" e "apanhadas em adultério ou megera demais para viver com seus maridos". Ele descreveu sua aparência física como masculina: 'desenvolvimento muscular da estrutura... a feminilidade pode ser detectada apenas pelo seio’ [citado em Blair 2010: 98]'. (TAMALE, 2011, p. 15)

1 Tradução nossa do texto original: African women's sexualities, however, were characterised as the antithesis of European mores of sex and beauty and were labelled primitive. The 1860 s travel memoirs 
Os estudos de Sylvia Tamale são importantes para a quebra de uma visão eurocêntrica acerca dos valores africanos sobre sexualidade, e revelam que, enquanto os europeus viam o corpo e a sexualidade com pudor e medo, as cosmovisões africanas vão apontar para a necessidade de uma conexão entre corpo e espírito, sendo as práticas sexuais inerentes a todos os indivíduos e essenciais para o equilíbrio e o funcionamento dos ciclos da vida. Desde as civilizações africanas mais antigas, como as que habitavam a região do Rio Nilo, o amor e erotismo estiveram presentes como parte fundamental na vida das pessoas, havendo, inclusive, registros sobre sexualidade e erotismo nos textos encontrados nas pirâmides do Egito e em pinturas dos sarcófagos.

Para muitas religiões africanas, o sexo é um grande condutor de energia vital, é por meio dele que há conexões profundas entre os corpos humanos, é através das relações sexuais que ocorre a fecundação, e, portanto, a continuidade das linhagens da vida. É pensando nesse valor africano sobre corpo e sexualidade, que a filósofa nigeriana Nkiru Nzegwu cunhou o termo Osunality, que pode ser traduzido literalmente como Osunalidade, no entanto usaremos ao longo deste trabalho o termo original em inglês. Òsun é a divindade feminina representada sempre com um abèbè, uma espécie de leque, mas que na afro-diáspora foi representado também como um espelho, acessório que acompanharia Òsun nos seus banhos de cachoeira, no qual ela estaria sempre a se admirar e se enfeitar. Este arquétipo de Òsun, vaidosa e fútil, é carregado de valores ocidentais acerca do feminino, pois, no contexto Yorubá, Òsun transcende essas características sendo um dos orixás mais temidos devido ao seu grande poder de feitiço e força para guerrear. Em terras iorubanas, Òsun é ainda a cortadora de cabeças, temida por homens e mulheres, que lhe devem respeito e reverências. Ela é no Ayié (terra), o rio Osogbo, sereno na superfície e revoltoso na sua profundidade, seu abèbè não é simples indumentária, é uma potente arma de guerra empunhada contra aqueles que desafiam o fluxo de suas águas. No conceito de Osunality podemos refletir sobre uma concepção de sensualidade e sexualidade humanas, a partir dos arquétipos do orixá Òsun:

Ao simbolizar um conduto sexual e materno, Òsun representa uma energia pró-natalista, centrada na mulher e transformadora de vida que percorre e anima a vida. O capítulo Òsetúrá de Odù Ifá apresenta essa força como altamente sensual e sexual. As mulheres que tipificam essa força solar ostentam sua sexualidade abertamente e de forma totalmente inconsciente. ${ }^{2}$ (NZEGWU, 2011, p. 258)

of English explorer Sir Richard Burton, for example, described the women that he encountered in the kingdom of Dahomey (present day Benin) as 'hideous' and 'taken in adultery or too shrewish to live with their husbands'. He described their physical appearance as male-like: 'muscular development of the frame... femininity could be detected only by the bosom' (quoted in Blair 2010: 98) [...] (TAMALE, 2011, p. 15)

2 Tradução nossa do texto original: In symbolising a sexual and maternal conduit, Òsun represents a pronatalist, female-centred, life-transforming energy that courses through and animates life. The Òsetúrá chapter of Odù Ifá presents this force as highly sensual and sexual. Women who typify this 
Dessa forma, o conceito de Osunality nos traz uma concepção filosófica sobre os estágios desde o sexo à fecundação e depois ao nascimento, é a força de Òsun que habita o corpo feminino, e até mesmo o corpo masculino possui um caráter enérgico que potencializa o fluxo de energia que, para Nkiru Nzegwu, seriam o desejo, a excitação, o prazer, a concepção, o nascimento e o crescimento:

O fluxo não precisa resultar em concepção e nascimento, mas acarreta o princípio do prazer no cerne da cópula. Este princípio de prazer no cerne da energia criativa é metaforicamente referido como "Mel de Òsun", que chamo de 'Osunality'. A Osunality afirma a normalidade do prazer sexual e do erótico. Quando ausente na vida, o resultado é a animação suspensa ou estase, e como o capítulo Òsetúrá narra, a vida efetivamente para³. (NZEGWU, 2011, p. 258)

A Osunalityé uma força dialética e dinâmica que estabelece relações dualísticas de realidade e potencialidade no ciclo de vida e morte, bem como dualidades ricas e complexas na identidade sexual das mulheres, como por exemplo a figura da amante e da mãe, simultaneamente. Ainda para Nzegwu:

Epistemologicamente, Òsun é constituída por dois princípios: sexualidade e fertilidade, e uma elaborada sequência de processos. O primeiro princípio produz prazer sexual e o último, filhos. Construída como uma divindade feminina para funcionar como um dispositivo mnemônico, Òsun, como outras divindades femininas da fertilidade em toda a África, autoriza e reforça a sexualidade feminina sem negar a sexualidade masculina. Essas forças não são simplesmente guardiãs da fertilidade, mas também articulações teóricas dos processos de sexualidade e fertilidade ${ }^{4}$. (NZEGWU, 2011, p. 259)

Nzegwu faz ainda uma analogia entre as secreções vaginais e o mel, elemento ligado ao orixá Òsun, esse mel seria uma oferenda que o corpo da mulher oferece aos parceiros no momento do ato sexual e tem o intuito de estreitar os laços de

Òsun force brandish their sexuality openly and quite unselfconsciously. (NZEGWU, 2011, p. 258)

3 Tradução nossa do texto original: The flow need not result in conception and birth, but it does entail the principle of pleasure at the heart of copulation. This pleasure principle at the heart of the creative energy is metaphorically referred to as Òsun's 'honey', which I call 'osunality'. Osunality affirms the normality of sexual pleasure and the erotic. When absent in life, the result is suspended animation or stasis, and as the Òsetúrá chapter chronicles, life effectively halts. (NZEGWU, 2011, p. 258)

4 Tradução nossa do original: Epistemologically, Òsun is constituted by two principles - sexuality and fertility- and an elaborate sequence of processes. The former principle yields sexual pleasure and the latter, children. Constructed as a female divinity to function as a mnemonic device, Òsun, like other female deities of fertility all over Africa, authorise and reinforce female sexuality without negating male sexuality. These forces are not simply guardians of fertility, but also theoretical articulations of sexuality and fertility processes. (NZEGWU, 2011, p. 259) 
intimidade e união, que serão responsáveis pelo nascimento dos filhos e a perpetuação harmônica da espécie humana (NZEGWU, 2011, p. 259). A partir da análise deste estudo, percebemos que os africanos possuem concepções diferentes sobre o corpo e a sexualidade quando comparadas com as concepções eurocêntricas. Para muitas comunidades em África, as relações sexuais e afetivas são não só pessoais como são também sociais, sendo bastante valorizadas, respeitadas e incentivadas. Contudo, com a imposição dos costumes e práticas culturais europeias durante o processo de colonização, grande parte destas concepções tradicionais africanas foram se perdendo, para dar lugar àquelas adquiridas com a assimilação cultural. Destacamos esses conceitos sobre corpo e sexualidade, pois são importantes para compreendermos o lugar do corpo materno no cerne das discussões das pensadoras africanas e afro-diaspóricas.

\section{Ventre-templo feminino: ancestralidade e resistência da mulher beninense}

A literatura africana de autoria feminina busca trazer em seus escritos discussões importantes acerca da maternidade e do papel feminino neste aspecto social. As pensadoras africanas e afro-diaspóricas têm repensado este conceito, que é uma das mais caras problematizações feitas pelas feministas ocidentais, já que é visto como uma imposição patriarcal na qual a mulher torna-se mero objeto reprodutor da linhagem familiar. Além disso, dadas as circunstâncias capitalistas, em que a mulher precisa trabalhar e cuidar dos afazeres domésticos, a obrigatoriedade dos cuidados com os filhos transforma-se em mais uma sobrecarga de responsabilidade afetiva e econômica, que nem todas as mulheres se veem dispostas a levar. A professora e pesquisadora estadunidense Andrea O'Reilly, ao defender seu conceito de Feminismo Matricêntrico, afirma a importância de que mulheres mães possuem com abordagens feministas que contemplem sua condição de maternagem e respeitem suas vivências na sociedade:

[...] também acredito que as feministas não devem desprezar a maternidade para facilitar a desestabilização do gênero. Eu acredito que é possível argumentar simultaneamente que gênero é construído, que a maternidade importa e integra a subjetividade das mães e suas experiências no mundo. Na minha opinião, a apreensão sobre a diferença de gênero é o elefante na sala do feminismo acadêmico5. (O'REILLY, 2016, p. 204)

5 Tradução nossa do trecho original: "[...] I likewise believe that feminists should not disavow motherhood to facilitate this destabilizing of gender. I believe it is possible to simultaneously argue that gender is constructed and that motherhood matters and that maternity is integral to a mother's sense of self and her experience of the world. In my view, the apprehension over gender difference is the elephant in the room of academic feminism" (O'REILLY, 2016, p. 204). 
Outro conceito importante para compreendermos a maternidade é o da pensadora do feminismo negro estadunidense Patricia Hill Collins, que se debruçou sobre o entendimento da maternidade a partir das experiências das mulheres negras na sociedade estadunidense. Os conceitos de other-mothering e mothering of the mind ${ }^{6}$ dizem respeito às vivências contra-hegemônicas das mulheres pretas que entrelaçam as condições de raça, sexualidade e gênero, aliadas às condições políticosociais. Para Hill-Collins, o ato da maternagem das mulheres afro-americanas se assemelha aos modos comunitários africanos de criar seus indivíduos, baseados na cultura de educar as crianças a partir de valores que beneficiam toda a comunidade, sendo, portanto, muito comum os mais velhos aconselharem ou mesmo reprimir as crianças, pois consideram que tendo más condutas, esses indivíduos poderão afetar a convivência harmônica de toda a comunidade. Hill-Collins considera ainda que enquanto as mulheres brancas viam a maternidade como um empecilho para a sua inserção no mercado de trabalho, por exemplo, a mulheres negras e latinas elaboram meios de se ajudarem e revezarem na criação dos filhos para não serem excluídas do mercado de trabalho, seriam as other-mother, mulheres que auxiliam na criação dos filhos das mães que precisam, por exemplo, trabalhar fora (COLLINS, 2007, p. 278).

No contexto africano, o corpo feminino representa o sagrado, algumas sociedades o associam à fertilidade da terra, portanto, a função de gerar filhos é extremamente relevante e prestigiada socialmente. As mulheres africanas, semelhante à terra que dá a vida e nutre os seres humanos, veem-se representadas dentro das variadas cosmovisões africanas como essencial para o funcionamento do ciclo da vida. Socialmente, algumas tradições conferem não só às mulheres o papel do maternar, mas sim a todos os indivíduos, biologicamente ou não, ligados a estas mulheres e aos seus filhos. A ativista e pesquisadora nigeriana Catherine Acholonu, pensando no seu conceito de Motherism em contraponto ao feminismo ocidental, irá incluir nas concepções do pensamento feminista africano a condição de mãe, sendo assim o termo Motherism um desdobramento da palavra mother (mãe, em inglês) (ACHOLONU 1995, p. 104). Acholonu defende uma:

[...] cooperação com aquilo que é a natureza é essencial para o entendimento do que é o Motherism e que a tarefa da Motherist é a de cuidar e proteger a coesão natural e essencial da família, da criança, da sociedade e do ambiente onde ela coexiste (ACHOLONU, 1995, p. 93).

O papel de Motherist pode ser desempenhado tanto por mulheres quanto por homens. A respeito disso, é interessante lembramos a afirmação de Oyèrónke Oyēwùmí de que é incompatível com os valores africanos o termo "mãe-solteira", pois isto liga à maternidade e o ato de maternar tão somente à instituição do casamento e à mãe e ao pai, quando na verdade os cuidados com as crianças devem

6 Traduzidos como "maternagem exercida pelo outro" e "maternagem da mente", respectivamente. 
ser responsabilidade de toda a sociedade na qual elas estão inseridas. A autora nos afirma que:

Na maioria das culturas, a maternidade é definida como uma relação de descendência, não como uma relação sexual com um homem. Dentro da literatura feminista, a maternidade, que em muitas outras sociedades constitui a identidade dominante das mulheres, está subsumida a ser esposa. Porque mulher é um sinônimo de esposa, a procriação e a lactação na literatura de gênero (tradicional e feminista) são geralmente apresentadas como parte da divisão sexual do trabalho. A formação de casais pelo casamento está assim constituída como a base da divisão social do trabalho. (OYĒWÙMÍ, 2004, p. 05)

Essas relações, inclusive, podem afetar o desenvolvimento psíquico e social das crianças no ocidente, pois elas relacionam o afeto materno a uma construção social de gênero, na qual sua mãe é a esposa de seu pai. Tais construções afetam um possível entendimento global sobre as várias formas culturais de organizações familiares, como nos alerta a professora nigeriana Bibi Bakare Yusuf, em seu texto Além do determinismo: a fenomenologia da existência feminina africana (2003):

[...] os proponentes das teorias do sexo dual não reconhecem que a maternidade ocorre dentro de contextos moldados por papéis e identidades socialmente desiguais para homens e mulheres. Somente uma teoria que é profundamente cúmplice do poder patriarcal, portanto, pode reduzir a identidade feminina ao aspecto materno. (YUSUF, 2003, p. o8)

Ademais, a função trabalho e maternidade em África, diferentemente do Ocidente, não são antagônicas, a imagem de mães carregando seus filhos nas costas enquanto vendem nos mercados ou laboram a terra, fazem parte do cotidiano de muitas sociedades africanas. Muito embora haja, evidentemente, que se ter cuidado para uma possível romantização da maternidade africana, colocando como natural a mulher exercer todas essas funções sem a participação efetiva do genitor da criança, já que estes países também são capitalistas e, consequentemente, as divisões desiguais do trabalho prevalecem na opressão do gênero feminino. O que buscamos aqui, é destacar os diferentes contextos nos quais diferentes mulheres estão inseridas e como alguns papéis colocados como femininos, a exemplo da maternidade, que é bastante problematizada pelas feministas ocidentais, precisam ser analisados de modo respeitoso com os múltiplos valores sociais, históricos e políticos existentes.

Nos romances Pour une poignée des gombos, de Sophie Adonon, e em Presqu'une vie, de Carmen Toudonou, a maternidade é uma das categorias temáticas que regem as vidas das personagens Abluimadji, Julienne, Régisette, Bäi, Séréna e Dansi. Em ambas as narrativas podemos encontrar tanto uma relação da maternidade com 
o sagrado quanto com algumas experiências tidas como tabus, como o abandono de recém-nascidos pelas mães. Em Presqu'une vie, o nascimento de Abluimadji está condicionado à crença de uma cobrança religiosa que, portanto, acarretará em uma gravidez, sendo única filha entre os seus irmãos, sua vinda ao mundo foi uma imposição dos vodouns à sua mãe:

Como ditava a tradição, era necessário dar a vida rapidamente a outra criança, para não correr o risco de atrair a raiva dos deuses. Diante disso, Yèyimin não ousou exprimir nenhum desejo. E ela deu à luz a uma criança que nenhuma mulher poderia dar à luz no mundo, Abluimadji. (TOUDONOU, 2014, p. 26)

Essa ligação do sagrado com a maternidade também ocorre no romance Pour une poignée des gombos. A personagem Régisette dá à luz a Éros e o abandona no templo de Dan, por sua vez o bebê é encontrado por Dansi. Por ser uma mulher estéril, Dansi já havia feito diversas oferendas aos deuses para engravidar:

Inspirada pela experiência de sua genitora, Dansi foi consultar Dannon, o sacrificador de Dan. O santuário desse sábio se encontrava no bairro Adandokpodji, em Abomey. Dannon lhe prescreveu uma longa lista de objetos para o sacrifício. Era o preço a se pagar para receber novamente as graças de seu Deus, e a maneira de se cumprir seu desejo mais querido ${ }^{8}$. (ADONON, 2016, p. 63)

Embora fosse feliz em seu casamento, a ausência de filhos criava em Dansi um sentimento de incompletude enquanto mulher e esposa. Por isso, suas súplicas aos deuses eram recorrentes, ao se deparar com Éros abandonado não titubeou em acolhê-lo, acreditando ser uma resposta dos deuses aos seus pedidos, Dansi adota, assim, a criança abandonada, ofertando-lhe proteção e cuidado:

Sem hesitar, Dansi tomou o pequeno ser nos braços, exultante. Abraçando o bebê nos braços, ela se ajoelhou, encostou o rosto no chão para homenagear aquele que ela acreditava ser a fonte de sua felicidade, o vodoun, Dan. Ela se endireitou e ergueu o bebê em direção à têmpora, elogiou Dan que, aos olhos dela, acabara de realizar um milagre. Ela prometeu cuidar bem do filho,

7 Tradução nossa do texto original: Comme le prescrivait la tradition, il fallait vite donner vie à un autre enfant, au risque de s'attirer la colère des dieux. Sur ce coup là, Yèyimin n'osa émettre aucun vœu. Et elle mit au monde l'enfant qu'aucune jeune fille ne pouvait mettre au monde, Abluimadji. (TOUDONOU, 2014, p. 26)

8 Tradução nossa do texto original: S’inspirant de l'expérience de sa génitrice, Dansi alla consulter à son tour Dannon, le sacrificateur de Dan. Le sanctuaire de ce génie se trouvait dans le quartier Adandokpodji, à Abomey. Dannon lui prescrivit une longue liste d'objets sacrificiels. C'était le prix à payer pour rentrer dans les bonnes grâces de son dieu, et le voir exaucer son vœu le plus cher. (ADONON, 2016, p. 63) 
abençoando de todo o coração aquele poder oculto que lhe havia impulsionado a seguir por esse caminho, pois ela estava prestes a pegar outro atalho. Ela não parava de murmurar: "É o dia mais feliz da minha vida. Dan Aïdo-wèdo, sempre serei fiel a você e sempre farei o que você quiser'9. (ADONON, 2016, p. 66)

Em Presqu'une vie, a personagem Abluimadji, também vê-se obrigada a abandonar a sua filha ao nascer, visto que esta engravida de Henri quando estava comprometida para se casar com outro homem:

Eu concordei. Eu tinha feito meus cálculos. Como eu deveria ter cometido umas duas besteiras até aquele dia, eu deveria estar grávida de pelo menos dois meses. Por enquanto, eu não sentia nada. Apenas leves náuseas que, com meu isolamento, conseguia esconder sem que ninguém percebesse. Mesmo que mamãe já tivesse me achado "estranha" uma ou duas vezes, eu ainda tinha a situação sob controle. Mas, dentro de um mês ou dois, as coisas seriam muito mais complicadas. Minha barriga começaria a arredondar e meus pais logo levantariam suspeitas, então teriam certeza de que eu estava longe de ser virgem, e de que eu estaria grávida. Não ousei imaginar a reação deles ${ }^{10}$. (TOUDONOU, 2014, p. 141)

Mesmo recebendo apoio do pai da criança, Abluimadji não vê outra saída, a não ser o abandono da criança ao nascer. A personagem se encontra dentro de aspectos culturais e familiares que a impedem de escolher o homem com o qual deseja construir sua família:

Quando Doutèwé derramou a água em seu corpo, ela começou a chorar novamente. Ela não ficou em silêncio até o banho terminar. Doutèwé enrolou seu cordão umbilical em um pedaço de pano.

\footnotetext{
9 Tradução nossa do texto original: Sans hésiter, Dansi prit le petit être dans ses bras en exultant. Serrant le bébé dans ses bras, elle s'agenouilla, plaqua sa face contre terre pour rendre hommage à celui qu'elle croyait être à l'origine de son bonheur, le voudou, Dan. Elle se redressa et levant le bébé vers le temple en latérite, elle loua Dan qui, à ses yeux, venait d'accomplir un miracle. Elle promit de bien veiller sur l'enfant, en bénissant de tout cœur cette puissance occulte qui l'avait poussée à emprunter ce sentier, tandis qu'elle était sur le point de passer par un autre raccourci. Elle n’arrêtait pas de marmonner: « C'est le plus beau jour de ma vie. Dan Aïdo-wèdo, je te resterai toujours fidèle, et je ferai toujours ce que tu voudras. (ADONON, 2016, p. 66)

10 Tradução nossa do texto original: J'acquiesçai. J'avais fait mon petit calcul. Comme je ne pouvais avoir conçu que le jour des deux bêtises, je devrais être à un peu moins de deux mois de grossesse. Pour l'instant, rien ne se remarquient. J'avais juste de légères nausées qu'avec mon isolement, j'arrivais à cacher sans trop de peines. Même si maman m’avait déjà trouvée "bizarre" une ou deux fois, j’avais encore la situation en mains. Mais d'ici un ou deux mois, les choses seraient autrement plus compliquées. Mon ventre allait commencer a s'arrondir et mes parents auraient automatiquement des soupçons, puis la certitude que loin d'être vierge, j'étais enceinte. Je n'osais pas imaginer leur réaction. (TOUDONOU, 2014, p. 141)
} 
Na verdade, trouxe uma camiseta e a enrolou em torno dele. Em seguida, ela o embrulhou em uma tanga grande e colocou-o em um pequeno espaço aberto, no meio da grama. O bebê brincava com os punhos cerrados. Ela agora tinha aberto os olhos. Seu olhar estava fixo para uma estrela no céu e não parecia imaginar o que estava lhe acontecendo" ${ }^{\text {. }}$ (TOUDONOU, 2014, p. 159)

Com a ajuda de sua amiga Doutèwé, Abluimadji realiza o parto de sua filha e, logo em seguida abandona o bebê:

Olhei mais um pouco para aquela pequenina que não tinha pedido para nascer e que eu iria abandonar assim, no meio da natureza. Dei-lhe um beijo, desejando-lhe do fundo do coração boa sorte, depois a coloquei na grama. Antes de partir, enterramos a placenta e jogamos areia no local do parto ${ }^{12}$. (TOUDONOU, 2014, p. 161)

Após alguns anos longe de sua comunidade natal, Abluimadji retorna a sua cidade e ao participar de uma cerimônia que consagra novos iniciados ao culto dos vodouns observa uma criança que se destaca dentre as outras por ter semelhanças físicas às suas:

Essa garota deveria ser a mais jovem de todas. E então, percebi

11 Tradução nossa do texto original: Quand Doutèwé lui versa l'eau sur le corps, elle se mit encore à pleurer. Elle ne se tut que quand le bain fut terminé. Doutèwé lui enveloppa le cordon ombilical dans un bout de tissu. Puis elle lui porta le tee-shirt ou plus précisément l'en enveloppa. Ensuite, elle l'emballa dans un grand pagne et la posa sur un petit terrain dégagé à l'écart, au milieu des herbes. Le bébé jouait de ses petits poings fermés. Elle avait maintenant ouvert les veux. Elle avait le regard comme fixé sur une étoile dans le ciel et ne semblait pas prendre la mesure de ce qui lui arrivait. (TOUDONOU, 2014, p. 159)

12 Tradução nossa do texto original: Je regardai encore un moment cette petite qui n'avait pas demandé à nâitre, et que j'allais abandonner ainsi, en pleine nature. Je lui fis un baiser en lui formulant intérieurement les meilleurs souhaits, puis je la posai dans l'herbe frâiche. Avant de partir, nous avons enterrâmes le placenta, et nous jetâmes du sable sur les lieux de l'accouchement. (TOUDONOU, 2014, p. 161)

13 Tradução nossa do texto original: Cette fillette devait être la moins âgée de toutes. Et puis, je trouvais qu'elle me ressemblait étrangement. Et si c'était ma fille? me demandai-je. Quand elle fut emmenée 
O que Abluimadji não sabia é que sua filha, após ser abandonada por ela, é encontrada pela esposa do Hounon, o sacerdote do culto local dos vodouns, com o qual Abluimadji também mantinha estreita relação já que era uma vodounsi. $\mathrm{O}$ sacerdote e a sacerdotisa, pai e mãe adotivos da filha de Abluimadji, acolhem a bebê abandonada, descobrindo pouco tempo depois que se tratava da filha de uma vodounsi e que, portanto, eles carregavam laços espirituais com aquela criança. O casal exerce a maternagem, não só pela escolha de adotar aquela criança, mas sobretudo pelo reconhecimento dos vínculos afetivos e o respeito que regem todos os indivíduos da comunidade:

A mãe adotiva de minha filha explicou-me que ela ficou um mês sem nome. Porque ainda tinham esperança de que seus pais viessem reivindicá-la e batizá-la. Quando foi revelado que a mãe era uma vodounsi, o casal decidiu nomeá-la enquanto aguardava um possível batismo de seus pais. Ela foi, portanto, chamada de Hounsi. Este é o primeiro nome dado à primeira filha de um vodounsi. Se ela fosse um menino, teria se chamado Hounsou ou Hounsa. Mas, naquele mesmo dia da cerimônia, ela mudou de nome. E passou a se chamar Nonfóoun; esse era o seu nome de iniciada. Em meu coração ela sempre será Sêna ${ }^{14}$. (TOUDONOU, 2014, p. 192)

Com isso, vale destacarmos a importância dos cultos religiosos tradicionais do Benim, em especial, o culto aos Vodouns, que são responsáveis por guiar as ações das personagens em diversos momentos das narrativas: "Eu vi claramente o meu Vodoun, e compreendi" (TOUDONOU, 2014, p. 95), dispara Abluimadji antes de sua iniciação ao culto ancestral de sua família. Esse ritmo de passagem era imposto por sua família e, a princípio, não era bem quisto pela personagem, porém no decorrer da narrativa, tal fato será fundamental para o empoderamento da personagem. Outro momento da narrativa que mostra uma relação de Abluimadji com a sua ancestralidade é quando o vodoun Mamy Water aparece para personagem, dias antes de seu parto e abandono de sua filha:

au couvent, j'essuyai une larme au coin de mes yeux. Je ne retrouvai le moral que quand elle revint au devant de la scène. Mais déjà, la cérémonie se terminait, et les hounsis se retiraient. Beaucoup de personnes mavaient reconnu et un cercle s'était formé autour de moi. Chacun voulait savoir où j'étais pendant tout ce temps, ce que j'étais devenue, etc. A tous, je répondais par un sourire. Je me portais bien, c'était l'essentiel. (TOUDONOU, 2014, p. 190)

14 Tradução nossa do texto original: La maman adoptive de ma fille m'expliqua qu'elleétait rester pendant um mois sans nom. Car l'on espérait encore ses parents viendraient la réclamer et la baptiseraient. Quand il fut révélé que la maman était une vodounsi, le couple décida de la nommer en attendant un éventuel baptême de ses parents. Elle fut donc appelée Hounsi. C'était le prénom que l'on donnait à la première fille d'une vodounsi. Si elle avait été un garçon, on l'aurait nommé Hounsou ou Hounsa. Le jour même, elle avait changé de nom. Elle s'appellait désormais Nonfôoun; c'était là son nom d'initiée. Dans mon coeur, elle restera toujours Sêna. (TOUDONOU, 2014, p. 192) 
Uma noite eu estava sentada na minha cama pensando sobre tudo isso. A casa inteira estava dormindo. Eu havia cochilado muito durante o dia para adormecer facilmente. Eu ouvi um barulho incomum na janela do meu quarto. Eu estava muito assustada. Meu coração estava disparado e não ousei fazer o menor gesto. Mas o barulho se repetiu. Era alguém trovejando na porta. Meus membros tremendo de medo, me aproximei da janela para olhar pelas venezianas. Alguém estava de pé. Era uma mulher. Eu realmente não acreditava em superstições. Mas, instantaneamente, a imagem de Mamy Water, a rainha das águas, esperando pacientemente por mim na janela passou pela minha mente. Voltei para sentar na beira da cama. Minha visitante insistiu gentilmente. Superando meu medo, voltei para a janela que abri. Minha amiga Doutèwé estava parada no pátio. $\mathrm{O}$ portão estava fechado há pelo menos duas horas. Achei que estava sonhando ${ }^{15}$ (TOUDONOU, 2014, p. 150)

Mamy Water, assim como o orixá Òsun, representa a força feminina das águas e está ligada, dentro das variadas cosmovisões africanas, às divindades responsáveis pela fertilidade e toda vida gerada nos ventres das fêmeas. Na afro-diáspora é possível vermos Òsun paramentada com uma cabaça presa às suas saias, é a representação dos cuidados desta divindade com o corpo materno feminino, é na cabaça que Òsun guarda seus remédios, feitiços e o segredo do nascimento. O ventre da mulher é templo de Òsun, nos movimentos-correntezas de reter e expulsar a vida. Sobre estes arquétipos das divindades femininas, a professora Elizabeth Souto Maior Mendes, comenta que:

[...] a maternidade é mais que apenas um destino biológico, sendo exaltada e ensinada em muitas culturas. A imagem da Madonna caracteriza o cristianismo; na tradição hindu, há a divindade Sarasvati, da sabedoria, e, na cultura africana, a MamyWata ("Mummy Water"), deusa das águas, frequentemente caracterizada como sereia. Em comum, o status de criadoras, provedoras, nutrizes e deusas, como se fosse uma regra universal, destino natural, característica inata de todas as mulheres, que aprendem, desde a mais tenra idade e geralmente com suas mães, que nutrir e cuidar é parte essencial e integrante de ser mulher.

15 Tradução nossa do texto original: Une nuit, j'étais assise dans mon lit, à penser à tout cela. Toute la maison dormait. J'avais trop somnolé pendant la journée pour facilement m’endormir. J'entendis un bruit insolite au niveau de la fenêtre de ma chambre. J'eus très peur. Mon ceur battait la chamade et je n'osais pas le moindre geste. Mais le bruit se répétait. C'était quelqu'un qui tonnait à la porte. Les membres tremblant de frayeur, je m'approchai de la fenêtre pour regarder à travers les volets. Quelqu'un était debout. C'était une femme. Je ne croyais pas vraiment aux superstitions. Mais sur le coup, l'image de Mamy Water, la reine des eaux, m'attendant patiemment à la fenêtre me traversa l'esprit. Je retournai m’asseoir au bord du lit. Ma visiteuse insistait doucement. Dominant ma peur, je retournai vers la fenêtre que j'entrouvris. Mon amie Doutèwé était debout dans la cour. Le portail était fermé depuis au moins deux heures de temps. Je croyais rêver. (TOUDONOU, 2014, p. 150) 
Fugir a esta imposição cultural é, portanto, uma tarefa quase impossível. (MENDES, 2017, p. 91)

A aparição de Mamy Water para a personagem Abluimadji, em um momento importante que é o de gerar outro ser humano, é bastante simbólico para compreendermos os aspectos intrínsecos às discussões sobre maternidade e maternagem nas culturas africanas. A personagem reconhece no sagrado a necessidade de fazer o possível para sua filha naquele momento, ainda que por meio do abandono, Abluimadji entende que maternar também seria dar a sua filha a chance de sobreviver. O mesmo sentimento podemos atribuir à Régisette, que escolhe o templo de Dan para deixar o seu recém-nascido, pois sabia que naquele lugar tão logo ele seria resgatado. Tal acontecimento, nos permite lembrar um itan de Òsun, muito difundido nas religiões afro-diaspóricas, nele fala-se que certo dia Òsun se banhava no rio e se mirava no espelho distraída, não percebendo que seu filho, o príncipe Logun Edé, caíra nas águas turbulentas do rio. Oyá, orixá feminino dos ventos e raios, passava por perto e ao ver a criança se afogando, a salva e a leva para seu palácio, sem entender como uma mãe poderia deixar isso acontecer com seu filho. Algum tempo depois, Òsun descobre onde seu filho se encontra e vai a sua procura, Logun Edé estava forte e saudável e aprendera com Oyá muitas táticas de guerra. Òsun agradece imensamente a Oyá por salvar seu filho e cuidado dele. Logun Edé, passou então a ter os cuidados maternos das duas divindades. É possível, a partir dessa narrativa sagrada do povo Yorubá, compreendermos o ato comunitário da maternagem dentro de um contexto africano.

Como divindades iyalodês, primeiras senhoras nos cultos tradicionais africanos, Mamy Water e Òsun são grandes feiticeiras e consideradas as mais antigas do panteão das deidades, carregam um poder ancestral de equilibrar todas as forças do universo. É, a partir do arquétipo dessas forças femininas, que a nigeriana Oyèronké Oyēwùmí cunha o conceito da Matripotência, em seu texto Matripotência: İyá nos conceitos filosóficos e instituições sociopolíticas [Iorubás]:

İyá está no centro do sistema baseado na senioridade, que simboliza o que descrevo como princípio matripotente. A Matripotência descreve os poderes, espiritual e material, derivados do papel procriador de İyá. A eficácia de İyá é mais pronunciada quando são consideradas em relação a sua prole nascida. O ethos matripotente expressa o sistema de senioridade em que İyá é a sênior venerada em relação a suas crias. Como todos os humanos têm uma İyá, todos nascemos de uma İyá, ninguém é maior, mais antigo ou mais velho que İyá. Quem procria é a fundadora da sociedade humana, como indicado em Oseetura, o mito fundador iorubá. A unidade social mais fundamental no mundo iorubá é o par İyá e prole. (OYĒWÙMÍ, 2016, p. 03) 
Carla Akotirene, em consonância com o pensamento de Oyèronké, nos lembra que também na diáspora as mulheres pretas, apoiadas aos valores ancestrais das Iyá, construíram espaços importantes de resistência e autoafirmação, como os terreiros de candomblé no Brasil:

Na diáspora brasileira, o prestígio político das grandes mães funciona estritamente nos terreiros de Candomblé, espaço de resistência negra restaurada por laços de afeto, família e hierarquia no qual uma Iya-lorisà carrega os valores ancestrais e culturais torneados de África. A mulher torna-se mãe dentro da relação com a ancestralidade, não-nuclear, podemos ser matrilinear, onde filhos independem dos laços sanguíneos e do estado civil. Significa então dizer que não somente homens adultos podem gozar de prestígios oportunizados pela antiguidade e postos na família não-nuclear e não-heterossexual. (AKOTIRENE, 2018, p. 79)

Temidas e respeitadas nas sociedades que as cultuam, as Iyá relembram o lugar de potência das mulheres africanas, encarnam o protagonismo feminino da origem e criação da vida e do equilíbrio entre os seres humanos. Lembram um passado ancestralmente feminino da mulher africana e de como esse olhar para esse passado potente possibilita a construção de um futuro autoconfiante para elas.

\section{Considerações Finais}

Em Presqu'une vie e Pour une poignée de gombos, tanto a narradorapersonagem quanto a narradora observadora que tecem as histórias, retratam a problemática de opressão feminina dentro do contexto social beninense, suas histórias vão sendo contadas a partir de um mise en abyme, o que a princípio podem parecer produções desfragmentadas, mas na verdade constituem-se em um labirinto de narrativas cuja estrutura é firme, pois as escritoras dão origem a textos que abrigam vozes de uma memória ancestral e com um olhar sensível para o modo de organização familiar beninense. As relações com a maternidade vivenciadas pelas personagens femininas desencadeiam acontecimentos

importantes nos romances e nos permite desconstruir concepções ocidentais sobre o maternar da mulher no Benim.

Observamos, ao longo das duas narrativas, que a maternidade, tida pelo feminismo ocidental como um ponto chave da opressão patriarcal, ganha outros sentidos quando pensada a partir dos lugares de vivências das mulheres em África. O primeiro sentido apresentado nos romances e que buscamos apresentar neste trabalho é o da relação da maternidade atrelada às vivências ancestrais de espiritualidade das personagens. Em diversas passagens das narrativas os vodouns são apresentados 
como agentes responsáveis por assegurarem a gestação e o desejo de ter filhos de algumas personagens. São essas divindades que anunciam a chegada das crianças, as protegem nos momentos de abandono materno e atendem aos desejos femininos de gerar as crianças.

Um segundo ponto de discussão, que as obras nos colocam, diz respeito a uma certa cobrança social para as mulheres que não engravidam, como o que ocorre com a personagem Dansi, que passa toda sua vida de casada tentando engravidar. Porém, é interessante destacarmos que muito dessas cobranças acontecem, não por uma necessidade da mulher em gerar filhos para garantir a linhagem do homem, já que muitas sociedades tradicionais africanas são matrilineares e sua descendência é atribuída às mulheres, mas sim por uma visão africana de que, biologicamente, é esperado que as mulheres gerem filhos e garantam assim a perpetuação dos indivíduos. A maternidade funcionaria, assim, como uma forma de realização pessoal das mulheres, que buscam atender às suas próprias expectativas enquanto sujeitos femininos. Destacamos ainda que os arquétipos das divindades femininas, que possuem ligações com a sexualidade, fertilidade e maternidade e que se encarregam de proteger os ventres femininos para tal acontecimento, como já foi mencionado, também contribuem para essa valorização africana do corpo materno.

Nos romances Presqu'une vie e Pour une poignée de gombos, a maternidade é também apresentada como um ato comunitário e não exclusivo da mulher que gesta, essa é a terceira discussão que buscamos compreender a partir das leituras dos romances. As crianças que sofrem o abandono materno contam com o afeto e cuidados de outros sujeitos para que sua existência esteja garantida, reforçando uma concepção africana de que todos os indivíduos em volta da criança devem assegurar o seu bem-estar. As escritoras Sophie Adonon e Carmen Toudonou, ao tratarem da temática do abandono dos filhos pelas mães, conseguem transpor um grande tabu social, sobretudo para as sociedades ocidentais. Ao mesmo tempo em que as angústias das mães ganham um olhar sensível e empático, levando os leitores para uma possível compreensão de que abandonar seus filhos era a única forma que as mães tinham de mantê-los vivos, assegurando também sua própria existência.

A maternagem, para as personagens femininas dos romances, significa toda a força e poder ancestrais que seu corpo materno detém. Gerando ou não biologicamente seus filhos e filhas, as mulheres que maternam nas narrativas revelam a matripotência que carregam. São através de seus corpos que as divindades femininas se personificam, as alegrias e as dores de viver o feminino são manifestações de resistência. Antes da guerra e dos rituais de feitiço, Òsun chega em terra reproduzindo um ilá de grito-choro, quase silencioso para não demonstrar fraqueza, mas, sobretudo, para não acordar os inimigos. Com seus passos lentos, mas firmes do ijexá, é que Òsun perpetua o ciclo da vida. O poder feminino é herança de Òsun, esse poder, como nos lembra a feminista Carla Akotirene, diz respeito aos corpos femininos detentores da potência ancestral de gerar outras vidas, não podendo ser marginalizados, mas sim ressignificados e potencializados. 


\section{Referências}

ACHOLONU, Catherine. Motherism: An Afro-Centric Alternative to Feminism. Owerri: Afa Publications, 1995.

ADONON, Sophie. Pour une poignée de gombos. Cotonou: Editions GG, 2016.

AKOTIRENE, Carla. O que éInterseccionalidade?. Belo Horizonte: Editora Letramento, 2018.

FANON, Frantz. Pele Negra, Máscaras Brancas. Tradução de Renato da Silveira. Salvador: EDUFBA, 2008.

HILL-COLLINS, Patricia. The meaning of motherhood in black culture and Black mother-daughter relationships. In: O'REILLY, Andrea (Org). Maternal theory: Essential readings. Demeter Press, 2007.

HOOKS, bell. Intelectuais Negras. Revista de Estudos Feministas. Tradução de Marcos Santarrita. Florianópolis, vol. 3, n. 2, 1995, p. 464-478. Disponível em: https:// periodicos.ufsc.br/index.php/ref/article/view/16465. Acesso em 02/12/2020.

MENDES, Maria Elizabeth Peregrino Souto Maior. O corpo materno em Without a name e Butterfly Burning, de Yvonne Vera: tensões, transgressões e resistências. Tese (Doutorado em Letras). João Pessoa: Universidade Federal da Paraíba, 2017.

NZEGWU, Nkiru. 'Osunality' - or African eroticism. In: TAMALE, Sylvia (orgs.). African Sexualities - A Reader. Cidade do Cabo, Dakar, Nairóbi e Oxford: Pambazuka Press, 2011, p. 253-270.

O'REILLY, Andrea. Matricentric Feminism: Theory, Activism, and Practice. Bradford: Paperback/Demeter Press, 2016

OYĒWÙMÍ, Oyèrónke. Conceituando o gênero: os fundamentos eurocêntricos dos conceitos feministas e o desafio das epistemologias africanas. Tradução para uso didático de Juliana Araújo Lopes. 2004. Disponível em: https://ayalaboratorio.files. wordpress.com/2019/o6/conceito-genero.pdf. Acesso em 24/12/2020.

Matripotência: İyá nos conceitos filosóficos e instituições sociopolíticas [Iorubás]. In OYẼWÙMí, Oyèrónkẹ. What Gender is Motherhood? Tradução para uso didático de Wanderson Flor do Nascimento. Nova Iorque: Palgrave Macmillan, 2016, p. 57-92. 
SILVA, Danielle de Luna. Maternagens na diáspora Amefricana: resistência e liminaridade em Amada e Um defeito de Cor. Tese (Doutorado em Letras). João Pessoa: Universidade Federal da Paraíba, 2017.

TAMALE, Sylvia. Researching and theorising sexualities in Africa. In: TAMALE, Sylvia (orgs.). African Sexualities - A Reader. Cidade do Cabo, Dakar, Nairóbi e Oxford: Pambazuka Press, 2011, p. 11-36.

TOUDONOU, Carmen. Presqu'une vie. Cotonou: Editora Plumes Soleil, 2014.

YUSUF, Bibi Bakare. Além do determinismo: a fenomenologia da existência feminina africana. Tradução para uso didático de Aline Matos da Rocha e Emival Ramos, 2003. Disponível em: https://filosofia-africana.weebly.com/uploads/1/3/2/1/13213792/ bibi_bakare-yusuf_-_al\%C3\%A9m_do_determinismo._a_fenomenologia_da_ exist\%C3\%AAncia_feminina_africana.pdf. Acesso em o6/11/2020.

Recebido em 08/03/2021.

Aceito em 29/04/2021. 